\title{
Depression and its psychosocial risk factors in pregnant Kenyan adolescents: a cross- sectional study in a community health Centre of Nairobi
}

\author{
Judith Osok ${ }^{1}$, Pius Kigamwa ${ }^{2}$, Ann Vander Stoep ${ }^{3}$, Keng-Yen Huang ${ }^{4}$ and Manasi Kumar ${ }^{5,6^{*}}$ (D)
}

\begin{abstract}
Background: Adolescent pregnancies within urban resource-deprived settlements predispose young girls to adverse mental health and psychosocial adversities, notably depression. Depression in sub-Saharan Africa is a leading contributor to years lived with disability (YLD). The study's objective was to determine the prevalence of depression and related psychosocial risks among pregnant adolescents reporting at a maternal and child health clinic in Nairobi, Kenya.

Methods: A convenient sample of 176 pregnant adolescents attending antenatal clinic in Kangemi primary healthcare health facility participated in the study. We used PHQ-9 to assess prevalence of depression. Hierarchical multivariate linear regression was performed to determine the independent predictors of depression from the psychosocial factors that were significantly associated with depression at the univariate analyses.

Results: Of the 176 pregnant adolescents between ages 15-18 years sampled in the study, 32.9\% $(n=58)$ tested positive for a depression diagnosis using PHQ-9 using a cut-off score of 15+. However on multivariate linear regression, after various iterations, when individual predictors using standardized beta scores were examined, having experienced a stressful life event $(B=3.27, P=0.001, \beta=0.25)$ explained the most variance in the care giver burden, followed by absence of social support for pregnant adolescents $(B=-2.76, P=0.008, \beta=-0.19)$, being diagnosed with HIV/AIDS $(B=3.81, P=0.004, \beta=0.17)$ and being young $(B=2.46, P=0.038, \beta=0.14)$.

Conclusion: Depression is common among pregnant adolescents in urban resource-deprived areas of Kenya and is correlated with well-documented risk factors such as being of a younger age and being HIV positive. Interventions aimed at reducing or preventing depression in this population should target these groups and provide support to those experiencing greatest stress.
\end{abstract}

Keywords: Adolescent pregnancies, Prevalence of depression, Psychosocial risk factors

\section{Background}

Adolescents are defined as people aged between 10 and 19 years according to the World Health Organization (WHO) [1]. Kenya is a country with an overwhelming population of children and youth, with more than half the estimated population of 36 million under the age of 18 years

\footnotetext{
*Correspondence: manni_3in@hotmail.com

${ }^{5}$ Department of Psychiatry, College of Health Sciences, University of Nairobi, Nairobi 00100 (47074), Kenya

${ }^{6}$ Research Department of Clinical Health and Educational Psychology, University College London, London WC1E 7BT, UK

Full list of author information is available at the end of the article
}

[2]. Two thirds of young people, worldwide are growing up in countries like Kenya where preventable and treatable health problems like HIV/AIDS, early pregnancy, unsafe sex and depression are common and where injury and violence remain a daily threat to their health, wellbeing and prospects in life [3-6]. In the African continent the rate of urbanization soared from $15 \%$ in 1960 to $40 \%$ in 2010 and is projected to reach $60 \%$ in 2050 [7]. Rapid urbanization has meant that economic growth and opportunities are centered in bigger cities and these pockets also fuel huge inequalities such as high unemployment and low incomes;

(c) The Author(s). 2018 Open Access This article is distributed under the terms of the Creative Commons Attribution 4.0 International License (http://creativecommons.org/licenses/by/4.0/), which permits unrestricted use, distribution, and reproduction in any medium, provided you give appropriate credit to the original author(s) and the source, provide a link to the Creative Commons license, and indicate if changes were made. The Creative Commons Public Domain Dedication waiver (http://creativecommons.org/publicdomain/zero/1.0/) applies to the data made available in this article, unless otherwise stated. 
inadequate housing together with tenure insecurity; and limited access to services such as health, education, safe water and sanitation, with limited physical and environmental infrastructure [8]. With the growth of urban informal settlements, populated with an emerging class of citizens known as 'urban poor'; a large number of whom are children and young people with poor access to health, education or even basic sanitation and resources in an additional challenge in several African counties including Kenya [9]. Poor family planning, sexual and reproductive health education and services and absence of robust maternity services are common problems in these informal settlements [10]. Adolescent pregnancy is then unintended and unplanned, fueled by socioeconomic and cultural factors and their prevalence aggravated by poor dissemination of sexual and reproductive health knowledge and access to adolescent friendly health services. In the urban resourcedeprived settlements it predisposes young girls to adverse mental health outcomes and enormous psychosocial stresses including stigma and discrimination [3].

\section{Being an adolescent: Risk factor for both perinatal health and depression}

Pregnancy is ordinarily a natural developmental process however evidence shows that a significant portion of adolescent fertility is unintended-either unwanted or mistimed-across countries in SSA [9]. Adolescent pregnancy is associated with poor health outcomes, including maternal deaths and injuries and adverse infant outcomes [11]. Eleven percent of all births occur in women between 15 and 19 years [12] with lower-and-middle income countries (LMICs) accounting for 95\% of births before 18 years. Almost $10 \%$ of girls in LMICs become mothers by the age of 16 , with the highest prevalence rates of early pregnancies seen in Sub-Saharan Africa (SSA) and in South Central and Southeast Asian regions [13] In Kenya, 26\% of adolescents become mothers between 15 to 19 years of age [14] About $41 \%$ of these pregnancies are unintended, $26 \%$ are mistimed and 15\% are unwanted [9]. These unintended and early pregnancies also make adolescents prone to STIs and HIV, adolescents experiencing an unwanted pregnancy are more likely to resort to abortions, which are often illegal and done by unskilled attendants leading to several pregnancy and birth-related complications [15]. Adolescent pregnancy predisposes young girls to adverse mental health [3] with depression and anxiety being the most common mental health disorders [16, 17]. Worldwide prevalence of depression during pregnancy is estimated to be between 11 and $18 \%$ [4, 18]. A higher prevalence is reported in women in LMICs with point prevalence of $15.6 \%$ during pregnancy and $19.8 \%$ postpartum $[19,20]$. Major depressive disorder (MDD) accounts for approximately $40 \%$ of YLDs yet mental health services in Sub-Saharan Africa are mostly restricted to tertiary psychiatric facilities [21-23]. Recent studies have shown that the prevalence of depression across subSaharan Africa to be high with antenatal depression reported to be 27 and 33\% respectively in Ghana and Côte d'Ivoire [24]. In Ethiopia, the prevalence of antenatal depression was $24.94 \%$ [25] and $39.5 \%$ in Tanzania [26]. In Kenya, a longitudinal study of women attending maternal and child health clinics in two major public hospitals in Nairobi (using Kiswahili version of EPDS with a cut off of 13 or more) found a prevalence of $18 \%$ for antepartum depression [27]. Given this context, and how rampant adolescent pregnancies are in LMICs like Kenya, the clear implementation gap has been to provide timely integrated sexual and reproductive health, maternity and mental health services in these informal settlements. For this implementation gap to be addressed we need robust epidemiological studies that look at depression prevalence, its severity and the associated risk factors that aggravate mental illness in this vulnerable group.

\section{Depression and mental health problems in pregnant adolescents}

In Kenya and other SSA countries, adolescent pregnancy is widely prevalent public health problem which poses a significant mental health burden. Despite this only a few studies on adolescent mental health needs during perinatal context can be found. Women living in LMICs are exposed to multiple risk factors for depression as their adverse life circumstances commonly include poverty and lack of family structure, low level of education, high rates of HIV/AIDS diagnosis, stigma and lack of social support [28-31]. There is a huge evidence now which suggests that the risk of depression is heightened when there is a previous adolescent pregnancy, low partner age, and adolescents whose mothers themselves had early unintended pregnancies [32, 33]. Furthermore, there is evidence of an association between a mood disorder and concomitant alcohol and substance use in adolescents in SSA which presents additional pregnancy and birth related risks [34]. One study reported that 43 . $7 \%$ of adolescents attending public secondary schools sample in Nairobi had clinically significant depression scores; nearly the same proportion were detected with moderate to severe anxiety along with depression symptoms [35]. Our study aims to determine the prevalence of depression in pregnant adolescents living in a resource-poor urban settlement of Nairobi County and an associated objective is to identify related psychosocial risk factors accompanying depression in this vulnerable population.

\section{Method}

\section{Study design, population and setting}

We carried out a cross-sectional study assessing depression and associated psychosocial risk factors in pregnant 
adolescents attending a Maternal Child Health clinic at a Nairobi community health care center located within the informal settlement. The facility is operated through the County Council of Nairobi giving free maternity services and caters for low-and-middle income wage earners from nearby informal settlements. It receives between 12 and 15 pregnant women every day and operates every weekday. We recruited 176 participants between ages $15-18$ years using a prevalence rate of $13 \%$ from a study [36]; using Cochran sample size estimation (1977) for a cross-sectional study keeping alpha at $p<0.05$.

\section{Study procedures}

This study was approved by Kenyatta National Hospital and University of Nairobi Ethics Review Committee (approval no. P499/07/2015). We collected data between November, 2015 to January, 2016. The study's purpose was explained to the participants and their caregivers. A written informed consent was signed based on willingness to participate in the study and for future uses of data, such as publication, preservation and long-term use of research data. About 6.8\% $(n=12)$ of pregnant adolescents we approached during data collection declined to participate in the study and despite our assurance of anonymity and confidentiality, it was mostly due to a strong feeling of stigma associated with their pregnancy. We suspect that their partners or caregivers prohibited them from participation. Adolescent pregnancy has a significant social stigma associated with it in the community context where we were working.

Once data was collected, confidentiality was assured by other means such as by de-identifying the data by use of serial numbers and the paper data was kept in sealed boxes in the Department of Psychiatry office. The study was conducted in a small cubicle within the ANC clinic in the health facility. Participants completed the researcher-designed demographic and psychosocial risk factors questionnaire and PHQ-9 Kiswahili version. There was no incentive given for participation. The lead author, who carried out this study as part of her postgraduate research, is a trained clinical psychologist with wide experience in working with adolescents and young children in the informal settlements of Kenya.

The study team discussed the data collection, referral mechanisms and use of the tools with the lead researcher who collected all the data herself. The participants recording high scores with a cut off of $15+$ on the PHQ-9 were referred to one of two places: (a) Psychiatric clinic operated on Wednesdays within the facility or (b) provided alternative of the Youth/Reproductive Health Centre at Kenyatta National Hospital where they could be seen free of charge. Within this inquiry, we had a nested small qualitative study exploring participants' interpersonal, practical and cultural challenges and barriers to accessing depression and general mental health care. The substantive findings of this qualitative inquiry are under process [37].

\section{Measures}

\section{Research designed questionnaire}

We inquired from our participants about their living conditions, access to food, care and education, whether they lived with parents, relatives or partners, income source/s, parental and partner social support and education, alcohol/substance abuse, experience of sexual/domestic violence, and STI/HIV status. These are social risk factors known to be associated with adolescent pregnancy and are also commonly found in adolescents with depression.

\section{Perinatal depression screening tool}

We used Kiswahili translated version of Edinburgh Postnatal Depression Screen (EPDS) [38]. EPDS has demonstrated acceptable clinical utility as a screening scale in Kenya and SSA. Our study team at the University of Nairobi has been using it to assess perinatal depression including carrying out a formal Kiswahili translation of EPDS and cross-cultural emic-etic issues in translation [39] and it was this version of the tool that was administered orally to the participants. The lead researcher first gave the socio-demographic tool followed by EPDS. A cut off of 13+ confirmed presence of peri-partum depression. A cut-off of 13 is recommended for probable major depression and a cut-off of 10 is recommended for probable minor depression [40]. We used this instrument as a primary screener and to enhance comparability with other studies carried out in Kenya.

\section{Depression diagnosis and severity assessment}

We used PHQ-9 as our main outcome variable $(>15+)$ and also to identify severity [41], the higher scores are an indication of greater severity depression.

Due to the peripartum nature of depression in adolescents, we used EPDS as a screener to identify likelihood of depression. We reported scores on PHQ- 9 for those who tested positive in EPDS primarily for test-retest reliability [42] and to categorize depression severity. The collection of data from these tools ensured internal validity through triangulation in evaluation of data and findings while external validity was obtained to the extent that these study findings can be generalized to other populations. During assessments, we targeted participants whose gestation period was 4 months and above and sought clarification on the duration of somatic symptoms of depression from normal pregnancy related symptoms. Participants who scored above $>=15+$ on PHQ-9 (i.e. from moderately severe category onwards) were considered to have symptoms of depression and were therefore referred for specialized care. 


\section{Statistical analysis}

SPSS version 22 [43] was used in data analysis. The association between depression and its psychosocial correlates was determined in two ways. Firstly, we divided our sample into two groups (depressed and non-depressed according to PHQ-9 cut-off score 15+ or more) and compared these groups using chi-square test. Secondly, we assessed each potential correlates with the PHQ-9 score using independent samples $t$-test and ANOVA. Hierarchical multivariate linear regression analyses were performed to determine the independent predictors of depression from the psychosocial factors that were significantly associated with depression at the univariate analyses. We ran regression analysis by entering the participants' socio-demographical variables into Block 1 , followed by other characteristics/ conditions in Block 2. There were no missing data for all the independent and dependent variables. Prior to running the analysis, all assumptions were checked including univariate/multivariate normality, linearity, homoscedasticity and diagnostic testing for multicollinearity and independence of errors. After checking for univariate normality, the PHQ depression scores was transformed by a two-step approach using inverse distribution function (IDF) using maximum likelihood estimator (MLE) in which we retained the original series mean and standard deviation to improve the interpretation of results. The level of statistical significance was kept at $P<0.05$, all tests were two sided.

\section{Results}

\section{Sample characteristics}

The socio-demographic characteristics associated with depression in our sample can be found in Table 1. Over half of our sample was 18 years of age, most had had primary but not secondary level of education and about half were married. A quarter was gainfully employed and just under half reported their family income to be less than 10,000 Kenyan shillings per month (less than 100 USD per month). A quarter lived in temporary shelters or houses and a large majority (91.5\%) attended the antenatal clinic as scheduled. Approximately a quarter of participants reported that they had not received any support from their partner or family members but just over half said they had received a positive response from their partners or parents once pregnancy was disclosed. A large number of our participants had experienced a recent traumatic event such as bereavement, loss of parent or close family member, abuse or feuds in their lives. A third had experienced domestic abuse and about $8 \%$ of our participants were adolescent living with HIV.

\section{Depression prevalence}

The EPDS scale was used to screen the risk of depression in our pregnant adolescent sample and we found 58\% falling under the category of a likelihood of depression. This was confirmed with the PHQ-9 diagnostic and severity assessment tool when a total of $33 \%(n=58)$ tested positive for clinical depression. Out of 176 participants, 38 (21.6\%) had no depression, 42 (23.9\%) had mild depression, $38(21.6 \%)$ had moderate depression, $30(17 \%)$ had moderate severe depression while 28 participants (15.9\%) were found to have severe depression (see Fig. 1).

\section{Associations between socio-demographic factors and adolescent depression}

We used PHQ-9 continuous scores as our main outcome to test associations with socio-demographic factors. On chisquare test of association, the age of the participants was significantly associated with their depression status, $X^{2}{ }_{(1}$, $N=176)=8.84 ; P=0.012$. All of the 27 younger participants (ages 15-16) were depressed, as were the majority of older participants. Of the 176 pregnant adolescents of ages 1518 years sampled in the study, $32.9 \%(n=58)$ tested positive for a depression diagnosis using PHQ-9 cut-off of 15+. We detected a significant difference those who were depressed and not depressed using PHQ-9 cut off on educational level, marital status, living with parents, monthly income (where we found an inverse relationship, adolescents who were in households earning more than 15,000 kes/per month had higher depression, $X_{(1, N=176)}^{2}=27.59 ; P<0$. 001), housing type, receiving social support, experienced stressful event or substance abuse, attending ANC clinic, experiencing domestic violence and having a HIV positive status (see Table 1).

Univariate analyses (see, Tables 1 and 2) findings indicated that younger age $(F(2,173)=18.63 ; P<0.001)$, unemployed $(F(1,174)=5.49 ; P=0.020)$, single status $\mathrm{t}_{(174)}=8.4 ; P<0.001$, living with parents $\mathrm{t}_{(174)}=-8.1 ; P<$ 0.001 , higher monthly income $(F(2,173)=3.42 ; P=0.035)$, temporary housing $\mathrm{t}_{(174)}=4.7 ; P<0.001$, not receiving social support $\mathrm{t}_{(174)}=8.0 ; P<0.001$, ambivalent to negative reaction to pregnancy $(F(2,173)=40.85 ; P<0.001)$, having children from before $\mathrm{t}_{(174)}=3.7 ; P<0.001$, experiencing a stressful event $\mathrm{t}_{(174)}=-8.2 ; \quad P<0.001$, those experiencing substance abuse $\mathrm{t}_{(174)}=-2.4 ; P=0.019$, not attending clinic regularly $\mathrm{t}_{(174)}=5.2 ; P<0.001$, those experiencing domestic violence $\mathrm{t}_{(174)}=-7.8 ; P<0.001$ and HIV positive diagnosis $\mathrm{t}_{(174)}=-4.0 ; P<0.001$ were significantly associated with higher depressive scores.

\section{Overall psychosocial risk factors model using multivariate linear regression}

The results of multivariate linear regression using PHQ-9 scores as the dependent variable and 14 predictors in two blocks are shown in Table 2. The overall model with all the predictors were statistically significant and explained $55.4 \%$ of the variance in depression among the participants with $F(17,157)=11.46, P<0.01$. In Block 1 , the 


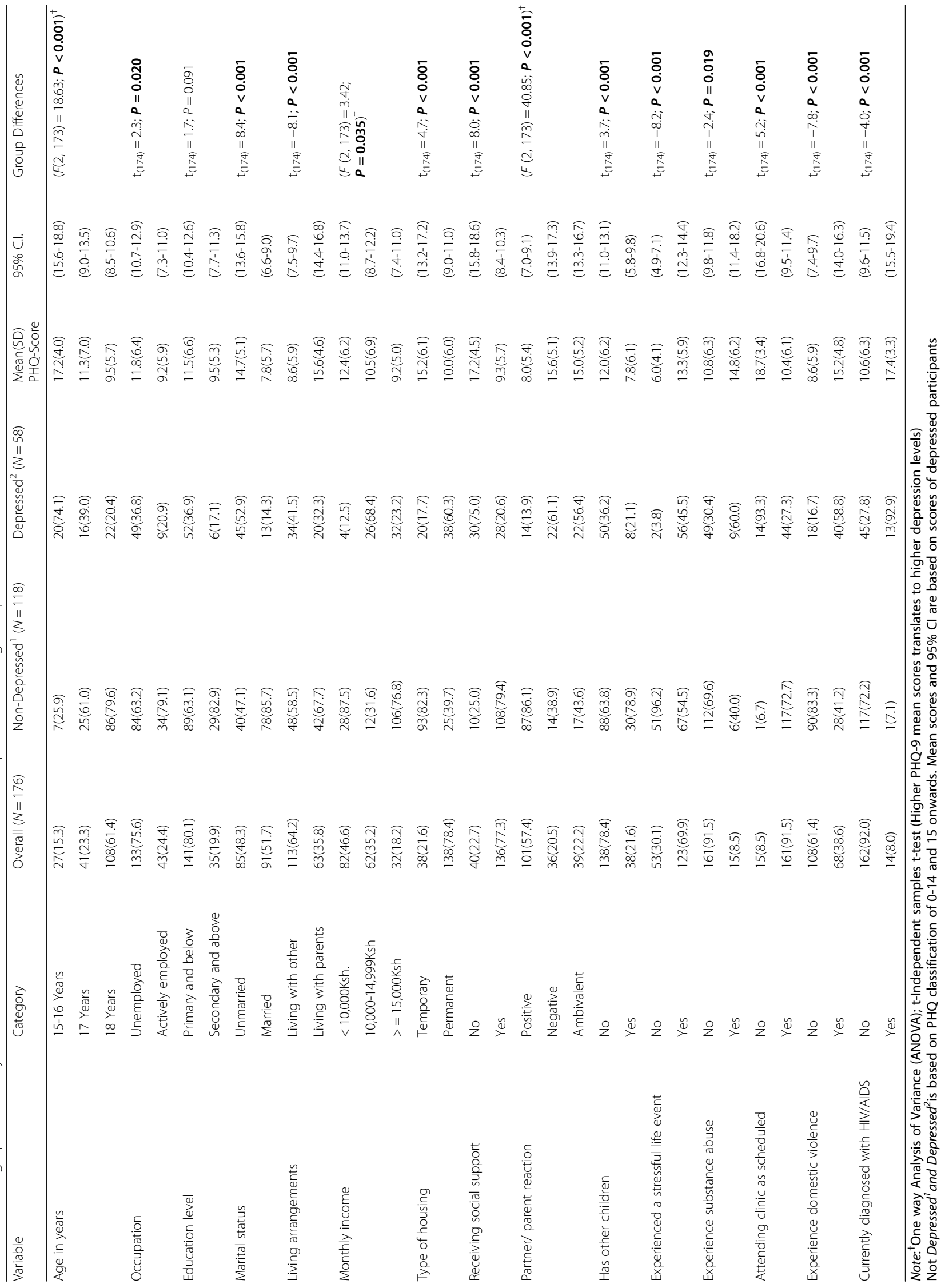




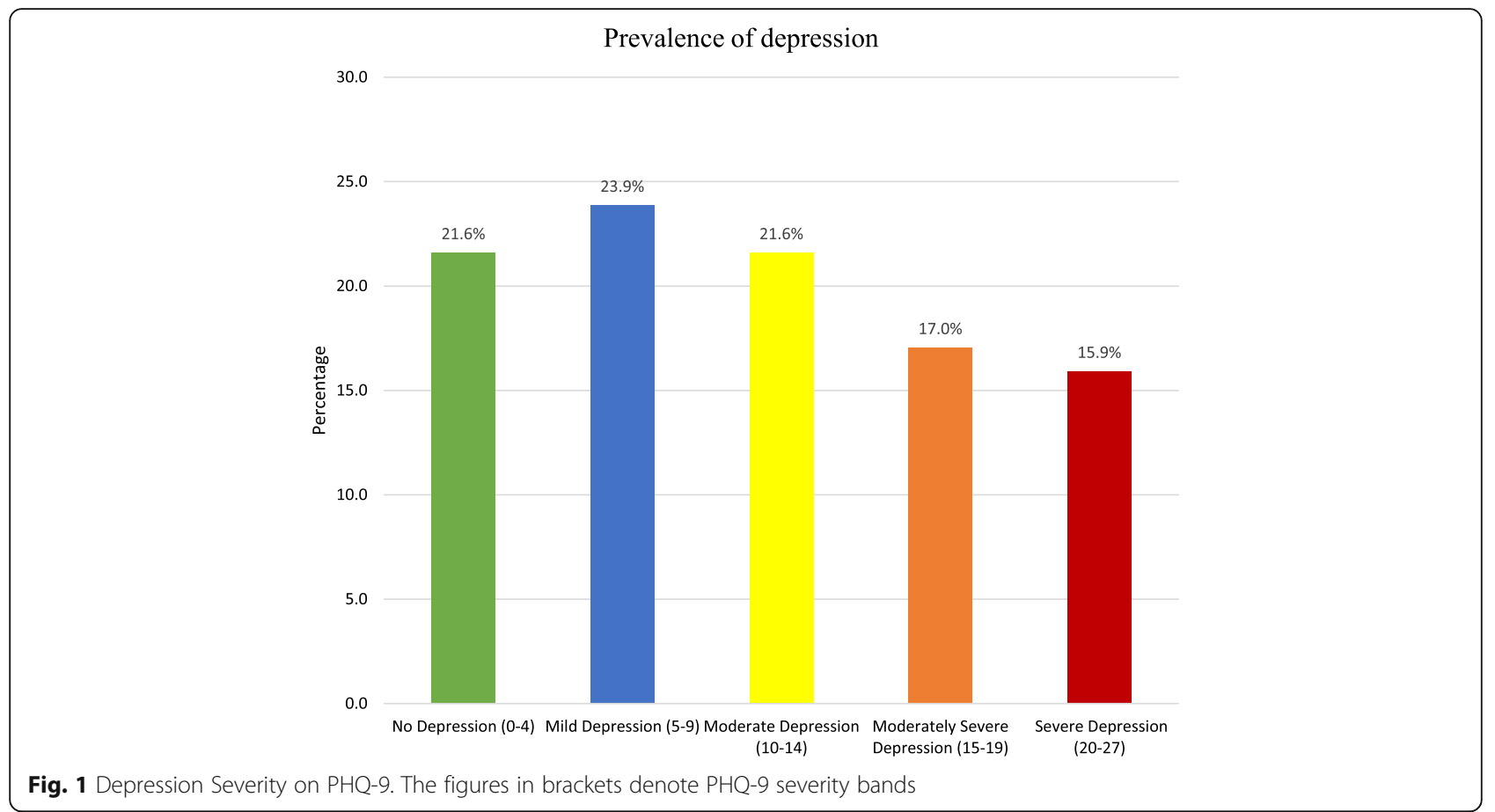

respondents socio-demographic characteristics i.e. age, occupation, marital status, living arrangements and income explained $37.2 \%$ of the variance in depression scores, which was statistically significant with $F(8,166)=12.31$, $P<0.01)$, in which age, type of housing and marital status were statistically significant $P<0.05$. In Block 2 , other participants characteristics uniquely explained a statistically significant amount $18.1 \%$, of the variance of the of participants depression after controlling for socio-demographical factors in Block 1, with $F(9,157)=7.10, P<0.01$. Therefore, the two blocks of variables significantly contributed to the prediction of the participant's depression. After various iterations, when individual predictors using standardized beta scores were examined, having experienced $a$ stressful life event $(\mathrm{B}=3.27, P=0.001, \beta=0.25)$, the $a b$ sence of social support for pregnant adolescents $(B=-2.76$, $P=0.008, \beta=-0.19)$, being diagnosed of HIV/AIDS $(\mathrm{B}=3$. $81, P=0.004, \beta=0.17)$ and being of younger age $(\mathrm{B}=2.46$, $P=0.038, \beta=0.14$ ) were the independent correlates of depression.

\section{Discussion}

Our study findings that $32.5 \%$ of adolescents reported clinically elevated depression symptoms and that $15.9 \%$ of our sample had severe depressive features are in line with other SSA studies where prevalence of severe depression in pregnant adolescents is to be between 11 and $18 \%$ [9, 18, 43]. Our study identified four critical risk factors for depression such as having experienced an adverse event or extremely stressful life context, living with HIV/AIDS, absence of support from the partner or the family and being a younger adolescent. We found that $15.3 \%(n=27)$ of pregnant adolescents were of ages 15-16 years indicative of a fairly early sexual initiation in our participants. The early sexual exposure with a concomitant lack of information/ knowledge or freedom to exercise sound sexual protection and contraception is a widely discussed issue in Kenya and in SSA in general. Doyle et al. (2012) in a study addressing the sexual behavior of adolescents in SSA reported that up to $25 \%$ of 15-19 years old's across SSA are having sex before the age of 15 years [44]. Recent evidence suggests that young women are less likely to initiate sex if they are currently in school, with at least a secondary education and never married [9] and it is likely that pregnancy has resulted in dropping out of school for these adolescent girls who were between 15 and 16 years of age.

Other studies carried out in Kenya, Uganda and Ghana have pointed to an interplay of various social determinants associated with sexual and reproductive health such as poor education, high poverty and food insecurity, rigid social norms, and under-resourced health systems $[9,33$, 45-48]. Given that our study was carried out in a health facility that caters to a large number of families based in informal settlements, each of these environmental factors play a mediating role that needs to be examined further.

We identified HIV positive status to be another risk factor in our study. We know that depression and stigma may impede linkage to HIV care, and to adherence to antiretroviral therapy (ART), additionally literature also suggests that ARVs and HIV positive status increases both HIV-related internalized stigma and depression 
Table 2 Results of hierarchical multiple regression analysis on depression

\begin{tabular}{|c|c|c|c|c|c|c|c|}
\hline Variable & Category & Beta(S.E) & $\begin{array}{l}95 \% C . I \\
\text { Beta }\end{array}$ & $\beta$ & $P$-Value & $R^{2}$ change & $\begin{array}{l}F \text { - ratio } \\
R^{2} \text { change }\end{array}$ \\
\hline \multirow[t]{3}{*}{ Age in years } & 15 to 16 Years & 2.46 & $(0.1-4.8)$ & 0.14 & 0.038 & 0.372 & $12.3^{\mathrm{a}}$ \\
\hline & 17 Years & 0.32 & $(-1.3-1.9)$ & 0.02 & 0.701 & & \\
\hline & 18 years & Reference & & & & & \\
\hline \multirow[t]{2}{*}{ Occupation } & Employed & 0.11 & $(-1.7-1.9)$ & 0.01 & 0.903 & & \\
\hline & Unemployed & Reference & & & & & \\
\hline \multirow[t]{2}{*}{ Marital status } & Married & 0.00 & $(-2.6-2.6)$ & 0.00 & 0.999 & & \\
\hline & Unmarried & Reference & & & & & \\
\hline \multirow[t]{2}{*}{ Living with parents } & Yes & 1.11 & $(-1.5-3.7)$ & 0.09 & 0.403 & & \\
\hline & No & Reference & & & & & \\
\hline \multirow[t]{2}{*}{ Type of housing } & Permanent & -0.27 & $(-2.2-1.6)$ & -0.02 & 0.782 & & \\
\hline & Temporary & Reference & & & & & \\
\hline \multirow[t]{3}{*}{ Income } & $<10,000$ Ksh & 0.27 & $(-1.7-2.3)$ & 0.02 & 0.788 & & \\
\hline & $10,000-14,999$ & -1.04 & $(-3.0-0.9)$ & -0.08 & 0.286 & & \\
\hline & $>=15,000 \mathrm{Ksh}$ & Reference & & & & & \\
\hline \multirow[t]{2}{*}{ Receiving social support } & Yes & -2.76 & $(-4.8-0.7)$ & -0.19 & 0.008 & 0.181 & $7.1^{\mathrm{a}}$ \\
\hline & No & Reference & & & & & \\
\hline \multirow[t]{3}{*}{ Partner reaction } & Negative & 1.46 & $(-1.2-4.1)$ & 0.10 & 0.272 & & \\
\hline & Ambivalent & 0.96 & $(-1.4-3.4)$ & 0.06 & 0.429 & & \\
\hline & Positive & Reference & & & & & \\
\hline \multirow[t]{2}{*}{ Have other children } & Yes & -1.58 & $(-3.4-0.2)$ & -0.11 & 0.089 & & \\
\hline & No & Reference & & & & & \\
\hline \multirow[t]{2}{*}{ Experience a stressful life event } & Yes & 3.27 & $(1.4-5.1)$ & 0.25 & 0.001 & & \\
\hline & No & Reference & & & & & \\
\hline \multirow[t]{2}{*}{ Substance abuse } & Yes & 1.44 & $(-1.0-3.9)$ & 0.07 & 0.246 & & \\
\hline & No & Reference & & & & & \\
\hline \multirow[t]{2}{*}{ Experience domestic violence } & Yes & 0.99 & $(-0.9-2.8)$ & 0.08 & 0.292 & & \\
\hline & No & Reference & & & & & \\
\hline \multirow[t]{2}{*}{ Diagnosed with HIV/AIDS } & Yes & 3.81 & $(1.3-6.3)$ & 0.17 & 0.004 & & \\
\hline & No & Reference & & & & & \\
\hline \multirow[t]{2}{*}{ Whether attending clinic as scheduled } & Yes & -2.55 & $(-5.2-0.1)$ & -0.11 & 0.059 & & \\
\hline & No & Reference & & & & & \\
\hline$R^{2}$ & & & & & & 0.554 & \\
\hline
\end{tabular}

Note: ${ }^{\text {a}}$ Correlation is significant at the 0.01 level (2-tailed)

Beta -Unstandardized coefficient; $\beta$ - Standardized coefficient

[49-52]. We need adolescents to understand sexual and reproductive health decision-making much more clearly. Both HIV prevention and HIV treatment require basic skills in comprehending and digesting information (such as modes of transmission safe practices to avoid infection) and actioning it (learning life skills to negotiate safe sex practices with partners, avoiding sex to get material gains, and adhering to medication). We know that depression can impede that decision-making process [53] thus making adolescents more susceptible to high risk practices and behaviors.
The pathogenesis of depression is further magnified in the context of developing pregnancy in adolescents. A recent study on adverse life events and delinquent behaviors in adolescents from informal settlements on Kenya found that more than half of the adolescents lived in households characterized by either food insecurity or recent parental unemployment, and almost a fifth had dealt with multiple adverse events in their lives [54]. In such an environment where adolescent pregnancy means addition of another mouth to feed, the emotional, economic and social pressures multiply in the family leading 
to more internal conflicts and poor interpersonal relationships.

We found a negative correlation between presence of social support and depression status. Family and social support is a known protective mechanism in mitigating depression and mental health problems [23, 28]. However, given the research design we are unable to tease out the degree of dependence of these two variables.

Our study contributes to an understanding of how vulnerable pregnant adolescents living with HIV are to depression, social isolation consequently leading to poor utilization of health care and PMTCT services. We also interviewed a select group of participants and our survey findings tally with the lived experience of our participants mapped through the depression and psychosocial risk factors survey reported here [37]. Our findings suggest that the indicators for social support need to be multidimensional - covering parental, partner, educational and health contexts to assess the quality of support available to the young girls. Each one of these girls has unique familial, social and health realities that need to be accounted for in any psychosocial intervention development.

The strength of our work lies in the use of a robust depression diagnostic tool such as PHQ-9 to assess depression symptomatology further. Being a cross-sectional study carried out at a community health center in Nairobi, the study portrays a picture of depression, indicates severity and the association of probable major depressive disorder with psychosocial risk factors in the adolescent antenatal period. Despite addressing a gap in the literature around depression prevalence estimates for this sub-group of adolescents, our data is limited by design and cannot capture the causal directions of associations between the factors we studied and the same applies to the temporal sequence of development of depression in our adolescent participants. On hindsight, we would have liked to use more formal measures of social support, HIV related stigma, trauma and stress experience to identify the impact of these factors on our participants' depression. Using a clinical interview to formalize the diagnoses of depression would have added greater strength to the study. A larger sample size would minimize any type 1 and 2 errors in estimating depression in this vulnerable population. Another limitation of study is that we collected data in a peri-urban health facility context and that may not sufficiently map onto the constraints and specific circumstances of pregnant adolescents in the rural or other remote settings in Kenya.

\section{Conclusion}

Most evidence-based perinatal depression interventions in LMICs are focused on adults and there exists very limited understanding of depression related risk factors in depressed pregnant or parenting adolescents. Although a body of epidemiological research in adolescent pregnancies in LMIC context have established mental health problems to be dominant, for good intervention research vulnerable population specific risk factors need to be ascertained $[4,55,56]$ and our study fills in that gap in depression prevalence estimate and associated risk factors in pregnant adolescents. We hope our study would provide pointers to critical factors that a depression intervention could encompass.

WHO's Mental Health Treatment Gap Action Program (known as WHO mhGAP) [57, 58] argues for adoption of greater task-shifting models, low intensity and culturally adapted psychosocial models that would seek to inform mental health services implementation in resource constraint contexts. For pregnant adolescents in Kenya, we urgently need these components to be integrated in primary health care settings where we are likely to find young girls struggling with enormous social adversities and mental health challenges.

\section{Abbreviations}

ANC: Antenatal clinic; ANOVA: Analysis of Variance; ART: Anti-retroviral therapy; EPDS: Edinburgh Postnatal Depression Score; ERC: Ethics and Review Committee; KNH: Kenyatta National Hospital; LMICs: Lower and Middle income Countries; MCH: Maternal and child health; PHQ-9: Patient Health Questionnaire-9; SD: Standard Deviation; SRH: Sexual and reproductive health; SSA: Sub-Saharan Africa; STIs: Sexually transmitted Infections; UoN: University of Nairobi; YLD: Years lived with disability

\section{Acknowledgements}

We would like to thank our study participants, numerous MCH nurses and personnel who supported data collection as well as MEPI's continuous learning programs that helped all the authors to think further about this study. We also acknowledge contribution of Prof Francis Creed in mentoring Ms. Osok during a manuscript writing workshop held at the University of Stellenbosch in South Africa in 2016. We also duly acknowledge Albert Tele for his statistical support.

\section{Funding}

This research was part of MEPI's Mental Health Linked Award supported by National Institutes of Health/National Institute of Mental Health grant R25MH099132 where MK and AVK were co-investigators and JO was granted a fellowship under this award. MK and HKY are currently co-investigators in the NIMH funded U19 MH110001-01.

\section{Availability of data and materials}

The datasets used and/or analysed during the current study are available from the corresponding author on reasonable request. Original data will not be shared since it could contain information that could be traced back to participants and violate confidentiality and anonymity.

\footnotetext{
Authors' contributions

The study was carried out by JO who was awarded a fellowship under a Medical Education Partnership Initiative (MEPI) mental health linked student fellowship. JO collected data and carried out initial analyses of her survey, MK was her primary mentor and helped in conceptualization, writing up and conducting multivariate analysis. PK was her second supervisor who assisted during planning of the research concept and reviewed the manuscript. AVS assisted in designing the study and reviewing the paper for submission. $\mathrm{KYH}$ assisted in reviewing the manuscript and addressing the statistical comments. All authors read and approved the final manuscript.
}

\section{Ethics approval and consent to participate}

This study was approved by Kenyatta National Hospital and University of Nairobi Ethics Review Committee (Approval No. P499/07/2015). The study's purpose was explained to the participants and their caregivers. A written 
informed consent was signed based on willingness to participate in the study and for future uses of data, such as publication, preservation and long-term use of research data.

\section{Competing interests}

The authors declare that they have no competing interests.

\section{Publisher's Note}

Springer Nature remains neutral with regard to jurisdictional claims in published maps and institutional affiliations.

\section{Author details}

${ }^{1}$ Department of Psychiatry, School of Medicine, College of Health Sciences, University of Nairobi, P. O. Box 20386, 00100 Nairobi, Kenya. ${ }^{2}$ Department of Psychiatry, School of Medicine, College of Health Sciences, University of Nairobi, P. O. Box 19676 (00202), Nairobi, Kenya. ${ }^{3}$ Psychiatry \& Behavioral Sciences and Epidemiology, Child Health Institute, University of Washington, 6200 NE 74th Street, Suite 210, Seattle, WA 88115-1538, USA. ${ }^{\text {DDepartment of }}$ Public Health and Child and Adolescent Psychiatry, New York University, New York, NY 10016, USA. ${ }^{5}$ Department of Psychiatry, College of Health Sciences, University of Nairobi, Nairobi 00100 (47074), Kenya. ${ }^{6}$ Research Department of Clinical Health and Educational Psychology, University College London, London WC1E 7BT, UK.

Received: 11 July 2017 Accepted: 24 April 2018

Published online: 18 May 2018

\section{References}

1. Adolescent health and development. WHO Available from http://uww.searo.who. int/entity/child_adolescent/topics/adolescent_health/en/. Accessed 10th Mar, 2018

2. UNICEF. (2014). Adolescents and youth; Kenya country Programme. https:/www.unicef.org/kenya/children_3793.html. Accessed on 10th Mar 2018.

3. Patton G, Sawyer SM, Santenelli JS, Ross DA, Afifi R, Allen NB, et al. Lancet commission on adolescent health and wellbeing. The Lancet. 2016; 387(10036):2423-78

4. Fisher J, Cabral de Mello M, Patel V, Rahman A, Tran T, Holton S, et al. Prevalence and determinants of common perinatal mental disorders in women in low- and lower-middle-income countries: a systematic review. Bul World Health Organ. 2012;90:139-49G. https://doi.org/10.2471/BLT.11.091850.

5. Sawyer RM, Afifi RA, Bearinger LH, Blakemore SJ, Dick B, Ezeh AC, Patton GC. Adolescence: a foundation for future health. Lancet. 2012;379(9826):1630-40.

6. Ki-moon B (2015). The Global Strategy for Women's and Children's Adolescent Health (2016-2030); Survive Thrive Transform. Every Woman Every Child. p. 4-6. https://www.unicef.org/earlychildhood/files/WHO_EWEC_ Supplement-bmj.pdf. Accessed 7 May 2018.

7. UN Habitat (2018). https://unhabitat.org/urban-initiatives/initiativesprogrammes/africa-urban-agenda-programme/ Accessed 10th Mar, 2018

8. UNICEF (2014); Kenya Situation Analysis of Children and Adolescents in Kenya 2014 Our Children, our Future. https://www.unicef.org/kenya/SITAN_ 2014_Web.pdf. Accessed 10th Mar, 2018.

9. Beguy D, Mumah J, Gottschalk L. Unintended Pregnancies among Young Women Living in Urban Slums; evidence from a prospective study in Nairobi City, Kenya. PLoS One. 2014;9(7):e101034. https://doi.org/10.1371/journal.pone. 0101034.

10. Beguy D, Kabiru C, Zulu E, Ezeh A. Timing and sequencing of events marking the transition to adulthood in two informal settlements in Nairobi, Kenya. Journal of Urban Health. 2011;88:318-40.

11. Liran D, Vardi IS, Sergienko R, Sheiner E. Adverse perinatal outcome in teenage pregnancies; is it all due to lack of prenatal care and ethnicity? J Matern Fetal Neonatal Med. 2012;0:1-4.

12. World Health Organization (WHO) (2014). Adolescent Pregnancy. http://www. who.int/maternal_child_adolescent/topics/maternal/adolescent_pregnancy/en. Accessed 12th Mar, 2018.

13. Atuyambe L, Mirembe F, Tumwesigye N, Annika J, Kirumira E, Faxelid E. Adolescent and adult first time mothers' health seeking practices during pregnancy and early motherhood in Wakiso District, Central Uganda. Reprod Health. 2008:5:13.

14. United Nation Population Fund [UNFPA]. (2013). Motherhood in Childhood; Facing the challenge of Adolescent Pregnancy. https://www.unfpa.org/ publications/state-world-population-2013. Accessed 7 May 2018.
15. Mumah J, Kabiru CW, Mukiira C, Brinton J, Mutua M, Izugbara C, Birungi H, Askew I. Unintended Pregnancies in Kenya: A Country Profile: STEP UP research report. Nairobi: African Population and Health Research Center; 2014. p. 1-200.

16. Alipour Z, Lamyian M, Hajizadeh E. Anxiety and fear of childbirth as predictors of postnatal depression in nulliparous women. Women Birth. 2012:e37-43.

17. Zachariah R. Social support, life stress and anxiety as predictors of pregnancy complications in low-income women. Res Nurs Health. 2009; 32(4):391-404.

18. Odeljimi O, Fuller $P$, Bellingham-Young D. Determinants of teenage pregnancy in Africa: implication for public health policy and practice. American Economic Journal: Applied Economics. 2011;3:1-34.

19. Howard LM, Piot P, Stein A. No health without mental health. Lancet. 2014; 384(9956):1723-4. https://doi.org/10.1016/S0140-6736(14)62040-7.

20. Whiteford HA, Degenhardt L, Rehm J, Baxter AJ, Ferrari AJ, et al. Global burden of disease attributable to mental and substance use disorders: findings from the global burden of disease study, 2010. Lancet. 2013;382: 1575-86.

21. World Health Organization (2011). Mental Health Atlas. Geneva, Switzerland www.who.int/mental_health/publications/mental_health_atlas_2011/en/. Accessed 12th Mar, 2018.

22. Grote NK, Bridge JA, Gavin AR, Melville JL, lyengar S, Katon WJA. Metaanalysis of depression during pregnancy and the risk of preterm birth, low birth weight, and intrauterine growth restriction. Arch Gen Psychiatry. 2010; 67(10):1012-24

23. Rahman A, lqbal Z, Harrington R. Life events, social support and depression in childbirth: perspectives from a rural community in the developing world. Psychol med. 2003;33(7):1161-7.

24. Bindt C, Appiah-Poku J, Te Bonle M, Schoppen S, Feldt T, Barkmann C, Guo N. Antepartum depression and anxiety associated with disability in African women: cross-sectional results from the CDS study in Ghana and Côte d'Ivoire. PLoS One. 2012;7(10):e48396.

25. Biratu A, Demewoz H. Prevalence of antenatal depression and associated factors among pregnant women in Addis Ababa, Ethiopia: A cross-sectional study. Reproductive Health. 2015;12(1):1.

26. Kaaya SF, Mbwambo JK, Kilonzo GP, Van Den Borne H, Leshabari MT, Fawzi $M C$, et al. Socio-economic and partner relationship factors associated with antenatal depressive morbidity among pregnant women in Dar es Salaam, Tanzania. Tanzan J health res. 2010;12(1):23-35.

27. Ongeri L, Otieno P, Mbui J, Juma E, Mathai M. Antepartum risk factors for postpartum depression: a follow up study among urban women living in Nairobi, Kenya. J Preg Child Health. 2016;3:288. https://doi.org/10.4172/2376$127 X .1000288$

28. van Heyningen T, Myer L, Onah M, Tomlinson M, Field S, Honikman S. Antenatal depression and adversity in urban South Africa. J Affect Disord. 2016; 203:121-9.

29. Merikangas KR, He J, Burstein M, Swanson SA, Avenevoli S, Cui L, Swendsen J. Lifetime prevalence of mental disorders in US adolescents: results from the National Comorbidity Study- Adolescent Supplement (NCS-A). J Am Acad Child Adolesc Psychiatry. 2010;49(10):980-9. https://doi.org/10.1016/j.jaac.2010.05.017.

30. Centers for Disease Control and Prevention. About the CDC-Kaiser ACE Study. https://www.cdc.gov/violenceprevention/acestudy/about.html. Accessed 12th Mar, 2018.

31. Hodgkinson SC, Colantuoni E, Roberts D, Berg-Cross L, Belcher HM. Depressive symptoms and birth outcomes among pregnant teenagers. J. Pediatr. Adol. 2010; https://doi.org/10.1016/j.jpag.2009.04.006.

32. Salazar-Pousada D, Arroyo D, Hidalgo L, Pérez-López FR, Chedraui P.(2010) Depressive Symptoms and Resilience among Pregnant Adolescents: A CaseControl Study. Obstetrics and Gynecology International, vol. 2010, 952493. https://doi.org/10.1155/2010/952493.

33. Juma M, Alaii J, Bartholomew LK, Askew I, Van den Born B. Understanding orphan and non-orphan adolescents' sexual risks in the context of poverty: a qualitative study in Nyanza Province, Kenya. BMC International Health and Human Rights. 2013;13:32. https://doi.org/10.1186/1472-698X-13-32.

34. Balogan O, Koyanagi A, Sticklay A, Gilmour S, Shibuya A. Alcohol Consumption and Psychological Distress in Adolescents: A Multi-Country Study. Journal of adolescent health. 2014;54(2):228-34.

35. Khasakhala LI, Ndetei DM, Mathai M. Suicidal behaviour among youths associated with psychopathology in both parents and youths attending outpatient psychiatric clinic in Kenya. Ann General Psychiatry. 2013; https://doi.org/10.1186/1744-859X-12-13 
36. Cochran WG. Sampling techniques. 3rd ed. New York: John Wiley \& Sons; 1977.

37. Osok J, Kigamwa P, Vander Stoep A, Grote N, Huang K-Y, Kumar M. (2018) Adversities and Mental Health Needs of Pregnant Adolescents in Kenya: Identifying interpersonal, practical and cultural barriers to care. BMC Women's health; special issue on structural violence and inequalities (under revision).

38. Cox JL, Holden JM, Sagovsky R. Detection of postnatal depression; Development of the 10-item Edinburgh Postnatal Depression Scale. British Journal of psychiatry. 1987;150:782-6.

39. Kumar M, Ongeri L, Mathai M, Mbwayo A. Translation of EPDS Questionnaire into Kiswahili: Understanding the Cross-Cultural and Translation Issues in Mental Health Research. J Preg child Health. 2015;2:134.

40. Manea L, Gilbody S, McMillan D. Optimal cut-off scores for diagnosing depression with the patient health questionnaire (PHQ-9): a meta-analysis. CMAJ : Canadian Medical Association Journal. 2012;184(3):E191-6. https://doi.org/10.1503/cmaj.110829

41. Sidebottom AC, Harrison PA, Godecker A, Kim H. Validation of the patient health questionnaire (PHQ)-9 for prenatal depression screening. Arch Womens Ment Health. 2012;15(5):367-74.

42. Corp IBM. IBM SPSS Statistics for Windows, version 22.0. Armonk, NY: IBM Corp; 2013.

43. Santos IS, Tavares BF, Munhoz TN, Manzolli P, De Ávila GB, Jannke E, Matijasevich A. Patient health questionnaire-9 versus Edinburgh postnatal depression scale in screening for major depressive episodes: a crosssectional population-based study. BMC Research Notes. 2016;9:453. https://doi.org/10.1186/s13104-016-2259-0.

44. Alvarado-Esquivel C, Sifuentes-Alvarez A, Salas-Martinez C. Depression in teenager pregnant women in a public hospital in a northern mexican city: prevalence and correlates. J Clin Med Res. 2015;7:525-33.

45. Doyle AM, Mavedzenge SN, Plummer ML, Ross DA. The sexual behaviour of adolescents in sub-Saharan Africa: patterns and trends from national surveys. Tropical Med Int Health. 2012;17(7):796-807.

46. Atuyambe L, Mirembe F, Johansson A, Kirumira EK, Faxelid E. Experiences of pregnant adolescents - voices from Wakiso district, Uganda. Afr Health Sci. 2005;5(4):304-9.

47. Kaye DK. Negotiating the transition from adolescence to motherhood: Coping with prenatal and parenting stress in teenage mothers in Mulago hospital, Uganda. BMC Public Health. 2008;8:83. https://bmcpublichealth.biomedcentral. com/articles/10.1186/1471-2458-8-83. Accessed 12th Mar, 2018

48. Gyesaw NYK, Ankomah A. Experiences of pregnancy and motherhood among teenage mothers in a suburb of Accra, Ghana: a qualitative study. International Journal of Women's Health. 2013;5:773-80. https://doi.org/10. 2147/IJWH.S51528.

49. Turan B, Stringer KL, Onono M, Bukusi EA, Weiser SD, Cohen CR, Turan JM. Linkage to HIV care, postpartum depression and HIV-related stigma in newly diagnosed pregnant women living with HIV in Kenya: a longitudinal observational study. BMC Pregnancy and Childbirth. 2014;14:400. https://doi.org/10.1186/s12884-014-0400-4

50. Yator O, Mathai M, Van der Stoep A, Rao D, Kumar M. Depression and associated risk factors in women attending PMTCT clinic at KNH, Nairobi, Kenya. AIDS Care. 2016;28(7):884-9. https://doi.org/10.1080/09540121.2016. 1160026

51. Aziato L, Hindin MJ, Maya ET, Manu A, Amuasi SA, Lawerh RM, Ankomah A. Adolescents' responses to an unintended pregnancy in Ghana: a qualitative study. J Pediatr Adolesc Gynecol. 2016; https://doi.org/10.1016/j.jpag.2016. 06.005.

52. Kumar M, Vander Stoep A, Grote N, Madaghe B, Yator O, Ongeri L, Polkonikova-Wamoto A, Osok J, Mochache K. Our journey to build capacity to implement and study an intervention to reduce depression among pregnant, Kenyan adolescents. Solving the grand challenges in mental health meeting held in Toronto, Canada from 2-5th June 2015. 2015. https://doi.org/10.13140/RG.2.1.1284.3685. Accessed 7 May 2018.

53. Kumar M, Huang K-Y, Otieno CJ, Wamalwa D, Madeghe B, Osok J, Njuguna Kahonge S, Nato J, McKay MM. Adolescent pregnancy and challenges in Kenyan context; perspectives of multiple community stakeholders. Global social welfare journal. 2017; https://link.springer.com/article/10.1007/s40609017-0102-8. Accessed 12th Mar, 2018

54. Vreeman RC, Scanlon ML, Marete I, Mwangi A, Inui TS, McAteer Cl, Nyandiko WM. Characteristics of HIV-infected adolescents enrolled in a disclosure intervention trial in western Kenya. AIDS Care. 2015;27(sup1):6-17. https://doi.org/10.1080/09540121.2015.1026307. Accessed on 10th Mar, 2018
55. Kabiru CW., Elung'ata P., Mojola S. A., \& Beguy D. (2014). Adverse life events and delinquent behavior among Kenyan adolescents: a cross-sectional study on the protective role of parental monitoring, religiosity, and selfesteem. Child and Adolescent Psychiatry and Mental Health, 8, 24. https://doi.org/10.1186/1753-2000-8-24.

56. UNAIDS UNFPA, WHO (2004). Seen but not heard: Very Young Adolescents Aged 10-14 Years. Geneva: UNAIDS https://www.unicef.org/Seen_but_not_ heard-Draft.pdf. Accessed 12th Mar, 2018.

57. Murray LK, Dorsey S, Bolton P, Jordans MJ, Rahman A, Bass J, Verdeli H. Building capacity in mental health interventions in low resource countries: An apprenticeship model for training local providers. International Journal of Mental Health Systems. 2011;5(1):30. https://www.ncbi.nlm.nih.gov/ pubmed/22099582. Accessed 12th Mar, 2018

58. mhGAP version 2.0. http://apps.who.int/iris/bitstream/10665/250239/1/ 9789241549790-eng.pdf?ua=1. Accessed 12th Mar, 2018.

\section{Ready to submit your research? Choose BMC and benefit from:}

- fast, convenient online submission

- thorough peer review by experienced researchers in your field

- rapid publication on acceptance

- support for research data, including large and complex data types

- gold Open Access which fosters wider collaboration and increased citations

- maximum visibility for your research: over $100 \mathrm{M}$ website views per year

At BMC, research is always in progress.

Learn more biomedcentral.com/submissions 